\title{
ORDINACIONS EN FAVOR DELS PESCADORS DE L'ALBUFERA I DE LA MAR DE LA CIUTAT DE VALËNCIA
}

\author{
Francisca Vendrell de Millás
}

El dia 10 de juny de l'any 1393 l'infant Joan, duc de Girona, va signar a València la confirmació $\mathrm{i}$ ordinació dels privilegis atorgats als jurats $\mathrm{i}$ comú de l'Albufera de València del temps de la conquesta ençà. Amb els anys sembla que no hi havia la cura que calia en la conservació de l'Albufera $i$ en les maniobres a fer per tal d'obtenir i protegir les entrades i sortides del peix i demés, la distribució de vedes i pesqueres, impostos, formes de venda del peix, saladura, sal, llenya, etc. com havia de fer l'anomenat quinter del rei. Perquè en tot el moviment d'activitats de l'Albufera, a més de la pesca, hi ha uns capítols molt importants, com són: la saladura del peix, per això hi ha unes disposicions dedicades a la sal, les salines i també per a l'ús de la llenya de la debe sa necessària per eixugar roba i estris destinats a tenyir o bullir les xarxes i cordam. Aquesta llenya sols es podia emprar als voltants de l'Albufera, però els pescadors no podien endur-se'n gens a casa seva, cosa que estava molt vigilada.

Les rendes que corresponien a la Corona a causa dels impostos del peix i de les pesqueres solien ser arrendades, cosa que esta ben ajustada en aquestes Ordinacions que avui oferim.

El rei Ferran d'Antequera tenia un tal sentit d'ordre i reforma administrativa que en el seu breu regnat assenyala unes fermes dreceres per als seus successors: les ordinacions de la ciutat de Çaragoça, les ordinacions de l'Aljama jueva de Caragoça, i la Pragmàtica del Papa Benet XIII. També va revisar i renovar les ordinacions de viles i gremis i confraries, feina molt freturosa en un regnat tan breu.

Avui tenim el goig d'oferir unes ordinacions encaminades a reorganitzar les activitats i la feina dels pescadors de la mar i de l'Albufera de València. Aquests es trobaven que tenien la documentació molt antiga i malmesa de tant utilitzar-la: els segells pendents romputs, alguns privilegis antics perduts, i les darreres ordinacions de l'infant Joan (després Joan I) no gaire ben conservades. Per això, com que el rei Ferran havia convocat Corts a València, aprofitaren l'avinentesa per pregar-li que, de conformitat amb 
les Corts, volgués confirmar els anties privilegis i concedir-los-en altres de nous, que eren fruit $i$ costum de les experiències observades, obtingudes $i$ també innovades al llarg dels anys en la pràctica de son ofici, tal com els els presentarem en una nova $i$ interessant redacció que avui oferim, ordinacions confirmades $i$ aprovades a València el dia 10 de juny de l'any 1415.

Ja hem esmentat que el producte dels impostos del peix de l'Albufera solien los reis arrendar-lo: tant les parts en el peix, com els impostos en moneda. La reina Violant en va fruir molts anys, de les rendes de l'Albufera i d'altres drets reials. Però sembla que no li escaigué gaire de gust l'activitat meticulosa de son ofici al batlle general de València Joan Mercader. Després que foren aprovades aquestes ordinacions, la reina Violant va aprofitar l'avinentesa de la situació d'altres rendes que també rebia en temps dels reis Joan i Martí per presentar al rei Ferran un programa de greuges contra Joan Mercader, i entre ells alguns de greus, queixant-se de la rigidesa en el compliment dels capítols, la qual la perjudicava. De moment no hem pogut trobar aquest plec de queixes presentat al Rei, que el batlle Joan Mercader li envià analitzant i rebutjant cadascuna de les acusacions i queixes que li dirigia la reina Violant. Les paraules de Joan Mercader, encara que sols siguin les que fan referència al peix, ens faran entendre la posició d'aquesta reina $\mathrm{i}$ les seves inisistents i neguitoses demandes:

Al quart cap. de la dita supplicació responch que yo no he emparades les dites rendes sinó per reparació e conservació de la cosa, ̧̧ és per què les çèquies e pesquera de la dita Albufera sien escurades, meses e sostengudes en lo estat que deuen ésser, en manera que la Albufera no.s perda e no peresca.

$\mathrm{Al}$ çinquen cap. de la dita spplicació responch que està en veritat que la dita senyora reyna no ha pus títol sinó que la Albufera tan solament li fon atorgada per lo senyor infant en johan per sustentació dels càrrechs de la $c(a) s a$ de la dita senyora infantesa. E aprés lo dit senyor infant fon rey e per consegüent ella reyna e exp(res)a lo dit títol. Aprés lo senyor rey en Martí, ab sa provesió data en Çaragoça a vint de deembre del any M Coc LXXXX VIII atorgà a la dita senyora que posqués arrendar la Albufera, salines e defesa per temps de quinze anys, appellat, emperò, en lo dit arrendament, lo batle general d'aquest regne. Aprés la dita senyora arrendà la Albufera e les salines per los quinze anys los quals fenexen a Nadal qui ve quant a la Albufera, e l'any qui ve quant a les salines, axí que finit l' any qui ve, la dita senyora no ha títol ni en propietat, ni en possessió, en les salines ne quant a la Albufera finit aquest any. Perquè appar clarament ue la dita senyora no ha títol alcú en la dita Albufera, salines e defesa en propietat ni en possessió. sinó per lo temps dessús dit. E durant lo dit temps yo no li he toquat en res. Es ver que y tinch hun guàrdia en la defesa a vostra messió qui guarda la dita defesa que alcú no la destrouexca. 
Tenint en compte la data de les ordinacions, el 10 de juny de 1415 , i la resposta del batlle general de València, el 24 d'octubre de 1415, és de suposar que la reina Violant va presentar les seves súpliques al rei Ferran entre aquestes dues dates. Ens atreviriem a pensar que aquestes últimes ordinacions de l'Albufera no foren rebudes de gaire bon grat per la reina Violant $i$ provocaren tot el seguit de queixes $i$ càrrecs que presentà al rei Ferran contra el seu batlle general. 

BUFFERA ET MARIS CIVITATIS VALENCIE.

1. Nos Ferdinandus dei gracia Rex Aragonum Siciliac etc... Exhibitis nobis reverenter pro parte probarum hominum piscatorum de la Albuffera et maris civitatis Valenciae quibusdem capitulis huiusmodi sericy: Molt alt et molt excellent princep et victorios Senyor: Com los Prohomens pescadors de la Albuffera et de la mar de la ciutat de Valencia del temps de la conquesta de aquest regne ança haien tengut et huy en dia tenen molts et diverses privilegis reals per los reys antecessors vostres als dits pescadors et comu de aquells donats et atorgats en et sobre los fets e negocis de la pesquera de la dita Albufera et de la dita mar de Valencia partida dels quals privilegis los dits pescadors per lo gran traspassament del temps han perdut et partida de aquells son molt antichs et vells, et en part consumats, e tots jorns que's envellexen (que s'envellexen) e consumen: E los segells de aquells se trenquen e guasten. E d'altra part els dits prohomens pescadors praticant $\mathrm{e}$ usant dela dita art de pescar expreriencia los ha declarat e mostrat quals e quantes altres coses son necessaries profitoses e clampnoses a les regalies de vos, senyor, e a conservacio del bon estament et profit del comu dels dits pescadors axi de la dita Albufera com de la dita mar les quals coses, senyor, los dits pescadors per lur fealtat son tenguts et obligats notificar e declarar a la vostra real magestat per provehir en aquelles. E los dits prohomens pescadors desigen molt que per vos senyor tots los dits privilegis antichs los fossen e sien novellament / (f.105 v.) atorgats, confermats loats et aprovats en les corts que vos senyor, a present en regne de Valencie celebrats. Suppliquent per tal molt humilment que sie merce de vos, senyor, provehir (e)statuir, ordonar et otorgar als dits prohomens pescadors los Capitols e Ordinacions següents: Primerament que tots los dits prohomens pescadors o partida de aquells tota vegada que ben vist lo será se puxen ajuntar et esser ensemps en la casa o cases que'l comu dels dits pescadors ha, te et possehex situada en la parroquia de sant Andreu en lo carrer deles Parres, una moltes et tantes vegades com mester será et ben vist los será et aqui tractar raonar et parlar deles coses justes et honestes toquants la dita pesquera et los fets e negocis de aquella, tota vegada a salvament de la fe e lealtat del dit senyor Rey et del profit deles regalies de aquell et del dit comun dels dits pescadors et non de alcunes altres coses desonestes, prohibides e vedades; exceptat en temps de guerra, ex en temps que no hagen o no coneguen qui es lur Rey/ e senyor en los quals casos e qualsevol de aquells no's puxen ajustar sino ab e de licencia del Batlle General que ladonchs será.

2. Item que-Is quatre jurats del dit comú dels dits pescadors qui ara son o per temps serán coneguen de totes et qualsevol questions qui sien o (speren esser entre los dits pescadors axi dela Albufera com dela mar e altres qualsevol persones pus les dites causes o questions sien o devalles de et per rahó dela dita 
pesquera ço es de exarcies lences, enansses, cordes, estrops, pega alquitrá, estopa, estres et altres qualsevol coses tocants la dita pesquera et los fets et negocis de aquella, les quals questions et debats los dits jurats puxen et hagen adicidir et decernir car de pla en pla de nua paraula seus scrits et altra figura de juhi et sens algu salari tant com toque los dits pescadors. Aço enadier que si alguna deles parts se tendrá per agreviada de la sentencia (s....cia) dels dit pirats que de aquella se puxe appellar a vostre Batlle General.

3. Item com segons forma de diverses privilegis reals lo tancar e obrir de la gola de la dita albufera pertange et sie acomanat e jaquit aconexença, ordenaçio e determinació dels jurats del dit comu los quals en les dites coses son molts abtes, sufficients et sperts com aquells sapien en quien dia et en quin loch e de quina amplaria se dege fer la dita tanca. E qui en quin dia et en quin loch e de quina amplaria se deu obrir la dita gola. E lo vostre quinter qui es tengut e obligat pagar los despenses de tancar a obrir cascun any la dita gola, moltes e diverses vegades jatsie request no vol tancar ni obrir la dita gola en temps legut de que son venguts grans et innumerables dans a vostres regalies et al comun dels dits pescadors et singulars de aquell; Entant que a present per colpa del dit quinter la dita gola es enrunada de arena et la dita Albufera et pesquera de aquella es quasi perduta et gastada la qual tanca es mur de la mar et dela dita Albufera; et per no tancar aquella en / (f. 106) cert temps del any de feyt se pert Io peix dela dita Albufera per gran desig que ha sen torna en la mar dou exit; $\mathrm{e}$ avegades no obrir la dita gola en cert temps redunda en gra e evident dan e perjuhi de vostres regalies et del dit comun e singulars de aquell car obrimt la dita gola entraria en la dita albufera gran copia del peix dela mar. E de poch temps ença de fet per colpa de males pasades s'es perduda la major part del peix del dit estany e s'es despoblada de peix la dita Albufera. Segons tot aço appar per diverses intimacions, requestes e protestacions e cartes publiques per los dits jurats e per lo Sindich del dit comun contra lo dit quinter fetes les quals, senyor a hull vos nostren. Suppliquen per tal molt humilment lo dit comun dels dits pescadors que placie a la vostra real magestat en e sobre les dites coses provehir e ordonar que'l tancar e obrir de la dita gola dela dita Albufera d'aqui avant sie jaquit e romanga a conexença declaració e determinació dels dits jurats de la dita Albufera qui ara son o per temps serán. E que'l dit vostres quinter qui ara es o per temps será tanqua e obre la dita gola e faça la dita parada en aquell dia e en aquell loch e de aquella amplaria que per los dits jurats e per quatre prohomes dels XXV consellers de aquell any concordantment seria ordonat, manat, dit o declarat. E si fer no u sobrá o no curará, que'l dit quinter sie encorregut en pena de sicent florins d'or d'Aragó per tantes vegades com contrafará aplicadors les dues parts a vos senyor e la terça part al dit comu. E que'l dit vostre Balle general si request ne será per lo sindich del dit comú façe e sie tengut fer real exequició en los bens del dit quinter de totes les dites penes. Et ultra la dita pena tantost prassat lo dit termini que donat o assignat li será los dits jurats e quatro consellers i varçosament facen tancar, obrir o adobar la dita tanqua a cost o messió del dit quinter com en tol's cassos sie gran perill en la triga. E per pagar lo loguer o salari de aquells qui en les dites cosses treballaran lo dit vostre Batlle General tantost com request ne será sens tota dilació face real exequció en bens del dit quinter. 
Emperó tota ora guardat e salvat lo interés e proffit del Senyor Rei e da ses regalies.

4. Item com lo canyiç qui es tanqua del peix qui es en l'Albufera e sens lo qual pers la gola s'es uberta lo dit peix se exiria de la Albufera e se'n iria a mar deje esser ficat per lo comu dels dits pescadors e per los compradors o arrendadors de aquell hoc encara lo dit canyiç deu esser ordonat, vist, regonegut, regit et administrat per los jurats del dit comú los quals son abtes a ficar, tancar, ordenar, regir e administrar aquell e no per alguna altra persona. Supplique per tal molt humilment lo dit comu que placie a la vostra real magestat provehir e ordonar quels dits jurats del dit comu e los compradors o arrendadors del dit canyiç fiquin lo dit canyiç, ordenen, vejen; regoneguenm regesquen/ $(f .106)$ e administren aquell e no alguna altra persona. E si lo contrari será feyt el contrafahent encorregue en pena de cent florins les dues parts a vos senyor applicadors e lo terç al dit comu. E açó declarat que'l quinter e jurats del dit comu james no hajen ni hauer puxen alcuna part en lo dit arrendament del dit canyiç per ço com si part hi han per cobdicia del peix que ix del dit canyiç lo dit quinter no vol tancar la gola quant mester hi es. Pero que en les dites coses sie quuardat lo profit e interes del dit Senyor Rey e de ses drets e regalies a coneguda del dit Balle General.

5. Item que 'ls dits pescadors del dit comun, axi de la dita Albufera com de la mar e cascum de aquells per si mateix puxen pendre los macips que ab ells (e)staran a certa part o seran afermats a certa soldada; si aquells se'n fogiran ans que hajen complit lo temps del afermament los quals puxen pendre o fer pendre en qualsevol ciutat, vila o loch de vostra jurisdictió. On aquells atrobats seran sens sang e sens cort. Per6 tantost com los hauran presos o fets pendre sien tenguts metre aquells en la presó comuna de Valencia e aqui estiguen preses continuament per XXX dies. E lo senyor o amo del dit pres sic tengut donar al dit pres un diner de pa cascun jom e pron aygua sens pus. E si dins los dits XXX dies lo dit pres se porá convenir ab lo dit seu amo encontinent sie absolt e gitat de la presó. Passats empro los dits XXX dies si lo dit pres no's sera convengut e no porá satisfer al dit son amo en aytal cars lo dit pres sia açotat per la ciutat de Valencia e sie gitat de la ciutat e regne de aquella. Et aytal açotat si bens haura paghera doble del deute que deurá al dit son amo. E si algun patro de galea de nau o de altre qualsevol vexell o altre qualsevol persona se'n menára lo dit macip, aquell qui'l se'n menará sie tengut pagar en doble al amo del dit macip lo prestech que se'n portará e totes les messions e despeses que'l dit amo per la dita raho fetes haura o sostendrá.

6. Item sie provehit e vedat als dits pescadors de la Albufera que de la festa de pasqua de rresurrectio tro a la festa de Sent Angel no pesquen ab almixares. pantenes faxets, alcudies, alfadida, brugienera, ab ret ni ab cop cech, saltades segures, ni rallar dessus, ni dejus lo canyiç, ni pescar de la pedra avall ab exarcia que tir tram ni ab batudes que baten, ni ab manses on prenen lo cabeçudell ni ab alcunes altres exarcies mentres la gola sie uberta ni puxen afitorar anguila en negun loch de la albufera sots pena de cremar la barcha e la exarcia e a perdre lo peix e de LX sols (solidos) aplicadors a vos señor.

7. Item que jatsie alcun no gos pescar en los vedats de la albufera de la festa de pasqua de resurreccio tro a la festa de sant miquel; pero sie statuite ordenat que los dits pescadors del dit comu pusquen pescar sens pena alcuna huyt dies ans 
de la festa de sant Miquel en los vedats de la pedra avall, ço es en les / (fol.107) pesqueres acostumades e no en los mitjans sots les proximes dites penes. E cascun any sien publicades ab crida les dites coses per lo Batle General per ço que los pescadors hajen raho de saber ho.

8. Item que'ls jurats del dit comu qui era, son o per temps seran amb los XXV concellers o la major part de aquells puxen donar licencia e licencies als dits pescadors del dit comu de pescar e temps vedat; hoc encara pusquen vedar que no pusquen en temps que tot hom pot pescar. Si aquells veuran, conexeran e trobaran esser profitos a les dites vostres regalies e al dit comu del pescadors aço enadit que si a alcu o alcuns es donada licencia de pescar tots los altres pescadors puxen pescar. E si alcu o alcuns es vedat que a tots sie vedat.

9. liem que algu en alguna manera no gos o presumesca pescar en torn de la gola aquella estant oberta çó es per una milla de cascuna part de la dita gola sots les penes supra proxime declarades. Pero encontinent tancada la dita gola cascu pusque pescar on se volrà per la part de la mar.

10. Item sie statuit e ordenat que'ls pescadors del dit comu no gosen o presumesquen traure la angila de lurs clots sens lo quinter o arrendador per ço que aquell sapie e veja quanta es o pot esser la dita anguila sots pena de LX sol(ido)s a vos aplicadors, aço declarat, que si denant dos testimonis dignes de fe lo pescador o pescadors demanaran o diran una vegada al dit quinter que vingue a veure traure la dita anguila e no y vendra, d'alli anant los dits pescadors sens pena alguna puxen traure o fer traure la dita anguila dels dits clots.

11. Item sie statuit e ordonat que les penes pecuniaries e altres quals sevol dessus e dejus contengudes e declarades per nos no sien ni puxen esser venudes ensemps ab les rendes de la dita albufera e si(h)o eren no i sien enteses ne compreses aus totes aquelles en e per tostemps sien e romanqen salves a vos senyor e succehidors vostres com axi sie atorgat per los reys passats al dit comu; e axi sie stilat usat e praticat de tant de temps ença que memoria de homens no es encontrari.

12. Item sie statuit e ordenat qué'ls broginers de la companya de la ciutat de Valencia pusquen legudament gitar sorts en les albengades o pesqueras en la plana de la albufera antigament ordenades, ço es lo Perllo, lo Tamaril, les Tesores, lo Corrall e lo Tor; e aquelles establir en la festa de Santa Maria de agost. E que null hom no'ls pusque conturbar en lurs pesqueres; e si (h)u fara perda lo peix aplicador les dues parts a vos senyor, e lo terç al comú $\mathrm{E}$ si l'almuçara e altra pesquera romanie buyda que la pusca pendre e si (se hi) pusque metre tot hom strany o privat per pescar en aquella e encara en quansevol de les altres pesqueres damunt dites que buydes romanguen. E si los dits broginers de la dita companya no seran apparellats, ço es (que) no seran X. companyons en cascuna / fol.107 v./ brogina en la dita festa de santa Maria de agost sperant companyons que sien de fora que puxen gitar les dites sorts en les dites albergades en la festa de santa Maria de setembre apres seguent et acollir cinquena et no d'aqui avant. E qui contrafara pach per pena LX sol(ido)s aplicadors a vos senyor les dues parts et lo terç al dit comu.

13. Item sie statuyt et ordenat que' 's primers pescadors del dit comu que ara son o per temps seran havents e tenints continuament o per los temps acustumats de lur propi barqua o barques, exarcia o exarcies de pescar en la dita albufera et en la dita mar e lurs macips, servidors et compayes (companyons) no puxem esser 
forçats per vos senyor ni per vostre Almirall o capità ni lochtinents de aquelles ni per alcun altre official anar o pujar en galea $o$ altres lenys, armades $o$ armats de alcuna armada vostra o daltri en l'esdevenidor faedora. Si donchs vos senyor en les dites galeres o lenys personalment no havets anar. E si lo contrari sera feyt cascun dels contrafahents sie encorregut en pena de dos milia florins aplicadors les dues parts a vos senyor e la terça al dit comu. Aço enadit que si vos Senyor, anats personalment en alcuna armada, o en alcuna galea o altre vexell; e los dits pescadors o alcun de aquells iran ab vos, e vos, senyor, vos escapolarets o remandrets o exirets de la dita armada, que' ls dits pescadors sien absolts e quitis e no sien tenguts seguir pus lo viatge al patró ni ab alcun altre.

14. Item sie statuit e ordenat que'Is pescadors del ditcomú qui ara son o per temps scran, en alcuna manera no sien tenguts ni obligats pagar alguna sisa o imposició per lurs rests, lences, çordes, esclops, pega, alquitrà, enanses, claus, estopa, posts o cloenda, ni per alguns altres exarats et coses a lur pescar acustumades, necessaries o oportunes, les quals de altri compraran o los dits pescadors ab lurs propies mans, o lurs mullers e companyes, faran o fer faran; manant als compradors et arrendadors de les dites imposicions qui ara son o per tenps seran, sots certes e grans penes a vos, senyor, aplicadores les dues parts, et al dit comú la terça part, et encara als administradors de les dites imposicions, qui ara son o per temps seran, et als honorables Justicia, Jurats et Concell de la dita ciutat de Valencia que no demanen, exhigesquen ni prenguen, demanar exhigir ni pendre facen ni permeten ni forcen als dits pescadors a pagar sisa alguna de e per rahó de les dites lurs exarcies et altres coses dessus declarades.

15. Item sia statuit et ordenat que 'ls pescadors del dit comú qui ara son o per temps seran, en alcuna manera nosien tenguts ni obligats pagar alcuna sisa $o$ imposicio del peix que'ls dits pescadors del dit comú pesquen axí en la mar com en la Albufera, los u quals pescadors del dit comú son aquests: Primerament tots los pescadors de Valencie et del terme de aquella, de Cullera, de Çuequa, de Soblona de Alcaycia, de Cilla, de Catarroja, de Macanaca, de Albal, de Alfafai, de Benitucet, de Alboraya, Meliana, Arbuxech, Albatar, Maçamagrell, Cebolla et Lo Puig. Manant als compradors et arrendadors de les dites imposicions, qui ara son o per temps seran, sots certes et grans penes / (fol. 108r.) a vos, senyor, applicadores les sues parts et al dit comú la terça part; et manar encara als administradors de les dites imposicions, et als honorables Justicia, Jurats et Concell de la dita Ciutat de Valencie que no demanen, exheguesquen ni prenguen, demanar, exhigir ni pendre faç en ni permeten ni forçen als dits pescadors a pagar sisa alcuna del dit pex de la mar e de la Albufera.

16. Item, senyor, com los pescadors del dit comú sien en pacífica et quieta possessió, de tant de temps entà que memoria de homens no es en contrari, et que baste a legitima preseripeió de comprar et pendre sal de les vostres salines de la Albufera de Valencie, per salar lo pex que'ls dits pescadors pesquen et prenen axí en la dita Albufera con en la dita mar. En lo qual peix de la dita Albufera vos, senyor, havets la quinta part et del peix de la mar havets lo terç de delme, la qual sal han acustumat pendre et reebre al for o preu que' 's dits saliners la venen en Valencie, deduit ço que la dita sal costa de portar de les dites salines a Valencie, o de alli hon lo prenen et reben. Et la qual sal acostumen comprar, pendre, haver et rebre bella, bona, blancaet neta. E vos, senyor, per les dites vostres parts semblantment ne sots en pacifica et quieta possessio del 
dit temps ençà, per salar la anguila et altre peix del dit vostre quint et terç del delme; car tot se sala ensemps ab la part dels dits pescadors. Et los saliners qui arrenden les dites vostres salines a vegades no volen vendre als dits pescadors la dita sal a nesgun for o preu, et avegades nee volen tant com la venen dins Valencie. Hoc encara a vegades los venen, donen e liuren mala sal, fort leja et molt terrosa, et a vegades neulada que amarga; les quals coses redunden en gran et irreparable dan de les regalies et dels dits pescadors car de la sal terrosa no's pot axí be salar lo peix com de la sal pura et neta de que a vegades se pert lo peix. Hoc encara si lo dit peix entre en fama de no sostenir port per mala sal, o de esser amarch per sal neulada, los mercaders no'l volran comprar per navegar. SUPLIQUE ;er tal, molt humilment, lo dit Comú dels dits pescadors que placia a la vostra Real magestat manar al vostre Batle General que force als dits saliners que ara son o per temps seran, sots certs et grans penes, que venen, donen et liuren als dits pescadors bona sal neta et sabrosa, no terrosa ni neulada et al for o preu que aquella vendran comunament en Valencie deduit ço que costarà de portar aquella dels salins o de ahi hon la reebran tro s Valencie. E que' 'ls dits pescadors no sien tenguts pagar lo preu de la dita sal sino's volran tro a la festa de Nadal o fins que la dita anguila serà venuda, com axí sie stat acustumat.

17. Item sia statuit et ordenar queí Mostasaf de la ciutat de Valencie et lochtinents de aquell, qui ara son o per temps seran, sots certes et grans penes en alcuna manera no's entremetan de levar les psts en les quals les pesca/dores (fol.108v.) mulleres dels dits pescadors et altres, venen lo peix qui es regalia vostra en la pescaderia de la dita ciutat; car la ordenació de les dites posts, e de les taules, et de tota la pescateria et limits de aquella pertangue als jurats del dit comú, et al Batlle General, et no al dit Mustaçafí ni a alcun altre official. Et los dits Jurats del dit comú ho han acostumat ordenar, regir et administrar continuament, vel quasi, del temps ançà que aquesta terra fon conquesta. Et axí los es stat donat et atorgat per diverses reys passats.

18. Item sia statuit et ordonat que'l Mustaçaff de la ciutat de Valencie et lochtinent de aquell qui ara son o per temps seran sots certes et grans penes en alguna manera no's entrameten de veure o coneser, ni coneguen del peix de la Albufera de la dita Ciutat ço es qual es venal, o deu esser venut o pot esser temgut a vendre en la dita pescateria, e qual no; com la conesença, decisió et determinació de les dites coses pertangue et pertany als Jurats del dit Comú. Et los dits Jurats del dit Comú han acostumat fer les dites coses, del temps de la dita conquesta ençà, et lo Batlle General et no alcun altre official.

19. Item sie statuit e ordenat que'ls jurats del dit comú qui ara son o per temps seran, hajen e puxen haver e rebrer tres diners per lliura per salari dels strangers, co es qui no seran pescadors; e qui no paguen ni contribuexen en los carrechs del comú de les questions e debats que'ls dits jurats, o aleú de aquells, determenaran, axí entre los dits strangers tots sols com entre stranger e pescadors. E, açó declarat, que' Is pescadors jamés no paguen alcun salari. Encara, açó declarat, que si lo demanador e lo convengut abduy seran strangers solament paguen entre abduy los dits tres diners per lliura de la valor de la demanda, questió o debat. E si lo un serà pescador e l'altre no que'l stranger tot sol pach los tres diners per lliura; hoc encara açó declarar: que'l dit salari a la dita rahó de tres diners per lliura no puxa muntar mes de cinquanta sólidos. 
20. Item sie statuit e ordonat que alcú de qualsevol ley, condicío o stament sie, en alguna manera no sie, gos o presumesque prestar sobre joch o en altra manera a negún macip dels pescadors del dit comú ni a alcú dels servicials e ajudants en la pesquera sobre roba alguna grossaque sie dels sits macips servicials e ajudants, o que sie de lurs amos o de altres; ni puxa adquirir o guanyar aquella a joch, ni per via de donació ni per via de compra. E qui lo contrari farà, e aquell qui la dita roba grossa en son poder pendrà e tendrà, perde lo preu e ço qui prestat li haura. E d'altra part sic encorregut en pena de XXX sólidos per cascuna vegada, applicadors a vos, senyor, les dues parts, e la terça part al dit comú. E d'altra part sie tengut restituir e donar la dita roba grossa francament sens alguna paga a aquell de qui presa la haurà. E que de açó sie feta crida pública cascun any una vegada en Valencia e en lo Grau de la mar, per ço que per algú ignorancia no puxe esser allegada.

21. Item sie statuit e ordenat que algú de qualsevol (fol. 109) ley, condició o stament sie, que port peix salat a vendre en la pescateria de la dita Ciutat en alguna manera no gos o presumesca portar ni metre ensemps en la dita pescateria sinó dos covens tant solament de cascuna berrejada; e com aquells seran venuts altres dos e axi successivament tro en la dita forma lo dit peix salat sie venut sots pena de LX sols. applicadors les dues parts a vos, senyor, e la terca part al dit comú. Inibint, senyor, al Mustaçaff e lochtinent de aquell que les dites coses no's entrameten sinó los dits jurats dels dits pescadors tant solament.

22. Item sia statuit e ordenat que'ls jurats del dit comú, qui ara son o per temps seran, sens incurriment de alguna pena puxen portar lurs armes honestament $\mathrm{e}$ bona, axi altres officials de vos, senyor, per honor de lur offici acostumen portar. Açó declarat que en cas de necessitat, ço es si aquells se temen de alcú, que cascú dels dits quatre jurats puxe anar $a b$ si terç ab armesarmes en sa pura deffensió.

23. Item com alguns senyors de lochs situats prop l'albufera e altres a lur franch arbitre, soven temptenpéndre e ab sí portar del peix que lurs vassalls pesquen e prenen en la dita albufera, e de aquell fan çó que'ls plau; lo qual peix tota vegada prenen contra volentat dels dits pescadors ans que aquell sia quintat per ço cpm los dits lurs vassalls pescadors no' Is gosen ni poden contrastar, ço que redunda en gran e evident dan e perjuhi de costres regalies. SUPPLIQUE per tal lo dit comú que placia a la vostra real magesta provehir e ordonar e manar que'ls dits senyors de lochs en alguna manera no gosen o presumesquen pendre ni prenguen ni facen pendre del dit peix sots pena de docents florins de lurs bens propis applicadors les dues parts a vos, senyor, e la terça al comú.

24. Item sie provehit, statuhit e ordenat perpetualment que'ls pescadors de la mar appellat pescadors de fora jamés no puxen esser separats ans perpetualment sien del comú e de la universitat e concordia dels pescadors de l'Albufera de la ciutat de Valencie. E sien tenguts contribuir ab aquells en totes coses e per totes com axí sie stat usat e praticat entre aquells del temps de la conquesta ençá; hoc encara axi es stat pronunciat e declarat provehit e ordonat per los reys passats, manat a qualsevol dels dits pescadors de fora, sots la ira e indignació vostra e sots certes e grans penespersonals e pecuniaries. que la present vostra provisió perpetualment tinguen e observen e en res no contravinguen. 
25. Item sia statuit e perpetualment ordenat que'ls pescadors axí de la mar com de la Albufera, sens encorriment de alguna pena, puxen tallar o fer tallar e mendre de la lenya de la devesa, tanta com mester ne hauran en lurs raffals axi en la mar com en l'Albufera, axi per calfar-se com per cuynare exugar lur roba, alquitranar lurs exarcies; pero que no en puxen portar a lurs cases; hoc encara puxen tallar o fer tallar e pendre vergues, rama e fulla de mata e de murta (fol.109v.) e de altres arbres per fer costeres e encetalls e per danprius de lur pesquera tansolament.

26. Item sia statuit que tots los pescadors axí de la mar com de la albufera que son del dit comú tota vegada que apellats sian per los dits jurats e per lurs andadors o missatgers, o per lures letres, sien tenguts venir a la casa del dit comú, o al loch o lochs que dit, nomenat e assignat los serà, per esser presents a la ordenació de les dites pesqueres, e per fer compartiments o tatxes de les quantitats que han o son tenguts pagar per dode senyor o per messions de comú, de missatgeries e altres coses toquants carrech o profit del dit comú. E per oyr compte e rahó dels dits jurats e de altres qui hauran administrat algunes quantitats de moneda per lo dit comú; o per esser a les alegries e festes que's acostumen fer per les novelles entrades dels reys e reynes sots certes penes, a coneguda dels dits jurats, açó declarant que'ls dits jurats del dit comú, si aquelles aquí apellats seran no vendran, puxen fer e ordenar tots los dits afers e negocis e totes les dites coses ab aquell que y seran, be axf com si tots hi fossen presents, la ausencia dels convocats e apellats en alguna cosa no contrastant.

27. Item que'ls quatre jurats del dit comú qui ara son, o per temps seran, cascun any en la vespra de la festa de Ninou puxen elegir e elegesquen vuyt bons homens per a jurats, ço es aquells que ben vista los serà, dementres empero aquells sien dels pescadors del dit comú de la albufera, dels quals lo vostre Batle General elegesca los quatre per a jurats del any seguent; dels quals VIII jurats novellament elets, lo Batle General sie tengut admetre et reebre los quatre dels dits huyt sens algun impediment, contrast o enbarch. E feta la dita eleccio los dits jurats nouells sien tenguts jurar en poder del dit vostre Batle General l'endemà o al menys dins tres joms après la dita festa de Ninou que be et lealment se hauran en lo dit offici de juraderia et guardaran lo profit e utilitat de les regalies de vos Senyor et lo profit del comú dels dits pescadors. E tant com en ells será faran justicia a les parts que davant ells pledeiaran e que onejaran tot parentesch e tot oy e mala voluntat apart posats.

28. Item que'ls dits quatre jurats que ara son o per temps seran, après que hauran jurat segons dit es dessús, puxen elegir e elegesquen. XXV. consellers los quals ajuden e donen consell als dits quatre jurats, tota vegada que requests ne seran: so es $X$. broginers et . $x$. battidors et cinch palangrers appellats pescadors de fora, los quals, xxv. consellers, feta la dita eleccio, juren e sien tenguts jurats en poder dels dits quatre jurats del dit comú que daran bo, leal e vertader consell als dits jurats tota vegada que request ne seran a profit de les regalies de vos Senyor e del dit comú.

29. Item que'ls quatre jurats del dit comú dels pescadors qui ara son o per temps seran hagen poder bastant de demanar, exhigir, reebre et recobrar en loch et en nom de tot lo dit comú totes e qualsevol quantitats bens et drets al dit comú per qualsevol persones degudes et pertanyents hoc encara de entrevenir en juhí et 
fora juyi/ (fol. 109v.) en demanda davant qualsevol jutge o jutges et en defenent davant vostre Batle General et jurar en anima de tots los dits pescadors del dit comú. E renunciar e concloure, e sentencies oir, e de aquelles, si mester seraे apellar; simdichs et procuradors constituir; et aquells revocar tantes vegades com ben vist los será. E fer àpoques, absolucions et diffinicions de ço que reebran. E encara pactes, composicions, avinences, transaccions, cessions e totes al tres coses fer et exercir que tot lo dit comu dels dits pescadors en e sobre les dites coses fer porie personalment hi ere. E tot lo dit comu promet tenir e servar tot ço que per los dits jurats et procuradors per aquells constituits sera feyt, proveit et enantat, e nou revocaran ni puxen revocar sots obligaciò de tos los bens del dit comú et singulars de aquell.

30. Item que'ls proòmens pescadors o la maior parte de aquells ab los dits jurats del dit comú et ab consell dels dits .xxv. concellers o de la maior par de aquells puxen fer et ordenar qualsevol capitols provisions et ordenacions legudes et previstes toquants los fets et negocis de la dita pesquera et altres redunden en augmentació, profit et utilitat de les regalies de vos Senyor et del dit comu dels pescadors tota vegada consentiment e ferma de vos Senyor o de vostre Batle General, lo qual haie et a fer la dita conexença, et prestar lo dit consentiment pus aquelles sien legudes bones et honestes liberalment et franca sens alcun salari o altre satisfaccio.

31. Item si alcunes persones, axi de la ciutat com altres, furtaran o levaran als dits pescadors de la mar o de la Albufera lurs sepieres, nanses o exarcies de junch o altres et ab si s'en portaran aquelles et o lo peix de aquelles; los malfeytors o damnificants et tots altres qui cometra crimo delicte en la Albufera o en la mar. et robatjes de aquelles, puxen esser convenguts civilment danant los dits quatre jurats del dit comù qui ara son o per temps seran; et aquells facen justicie a les parts del dan et dela pena o ban. Pero que del crim conegut i faça execució lo vostre Batlle General.

32. Item que alcun official de la ciutat et regne de Valencie no's entremete de conexer de alcuna questió que sie entre los pescadors de la mar et de la Albufera ni de les companyes de aquells, ni de altres qualsevol persones; pus les dites questions sien per coses toquants a pesquera et a coses servints en aquella, ni dels afermaments dels macips dels dits pescadors, ni de les soldades de aquells, ni si los dits macips asoldadats s'en fugiran ans que hage complit lur temps sots pena de mil florins; et als que als dits officials per la dita raho recorreran sino als dits jurats et Batle en son cars sots pena de cent florins aplicadors les dues parts als vostres cofrens et la terça part al dit comú.

33. Item que'ls dits jurats, qui ara son o per temps seran, puxen multar, punir, corregir et castigar, encara levar armes et arrestar sots (fol. 110v.)/certes penes en lurs cases, xoces o barraques als dients o temptants dir et fer contumelies o imjuries verbals o de fet, axi en presencia com en absencia dels dits jurats. E si mester será puxen aquells pendre sens sang et sens cort o fer pendre e metre en la presò. E les armes que hauran levades puxen vers si retenir tres dies per tolrre e levar bregues scandels et perills; et per reduir a concordia aytals breguejants o barallants. E si dins los dits tres dies los dits breguejants o barallants faran pau los dits jurats puxen tomar les dites armes a aquells de qui seran; en altre manera passats los dits tres dies los dits jurats sien tenguts donar aquelles al Justicia criminal de Valencie, si les dites injuries o bregues seran 
stades o fetes en la dita ciutat o en el camí anant a mar o a la Albufera tro als limits de aquella. E si aquelles seran stades dites o fetes a mar o a la Albufera sien donades a vostres Batle General. E si injuries actuals seran fetes en les quals hage nafres o altres ferides o maior esces, los dits jurats, sens sang et sens cort, puxen aquells pendre o fer pendre, o metre en la preso. Pero lo proces et punició de aquests aytals delinquents pertangue al dit Justicia criminal si les dites nafres o excesses seran fetes en la dita ciutat o en lo dit cami. E si seran fetes a mar o a la Albufera pertangue al vostre Batle General, de les quals multes les dues parts sien de vos Senyor, et la terça part dels dits jurats.

34. Item, sie statuit et ordenat que vostre Batle General et lo guardia et guardias de la Albufera, qui ara son o per temps seran, et lochtinents de aquells en alcuna manera no pusquen ni gosen ni presumesquen donar licencia a nengú de tenir bous ni vaques en la dita devesa com aquells et aquelles soven, et massa soven, esquincen, trenquen et consumen los filats et exarcies de fil dels dits pescadors et esfan les barraques. E cinquanta vaques o cinquanta bous consumen mes la devesa que tot quant bestiar ha en aquest regne, ans sien tenguts de vedar, castiguar et punir los contrafahents.

35. Item, sie statuit e ordenat que tantost que'ls pescadors de la companyia sien en lurs albergades apparellats de pescar ab qualsevol exarcies, los jurats del dit comú que ara son, o per temps seran, et no alcuna altra persona. tota vegada que ben vist los será. puxen ficar los senyals acostumats ficar; lo un al cap del Palmar vers les Salines velles et l'altre en la terra de Sollana.

36. Item, tots los dits pescadors del dit comú, axi de la mar com de la Albufera, suppliquen molt humilment, per si et per tots los altres qui per temps seran pescadors del dit comú, que placie a la vostra Real Magestat pendre en vostra real protecció, custodia, guiatge, comanda et salvaguarda a tots los dits pescadors del dit comú, qui ara son o per temps seran, et totes lurs mullers et tots lurs fills, familia, macips, servidors et ajudadors de aquells / (fol.111r.) e tots lurs bens que ara han e d'aquf avant hauran. En axi que alcu o alcuns en alcuna manera no gosen o pusquen per si o per altri, palesament o amagada, nafrar, injuriar, offendre ni fer alcuna violencia de paraula o de fet, ni fer alcun mal ni dan als dits pescadors del dit comú, mullers, fills, filles, macips, servidors e ajudadors de aquells ni bens lurs, sots incorriment de la ira e indignació vostra e sots pena de mil florins d'or d'Aragó per cascun contrafahent, applicadors les dues parts a vos, Senyor, e lo terç al dit comú dels pescadors ab totes les clausules en semblants guiatges acostumades, necessaries e opportunes de les quals penes sia feta execució per lo vostre Batle General. E que'l dit guiatge puxe esser notificat e publicat ab crida publica de dos en dos anys per ço que per alcu ignorancia no puxe esser allegada.

37. Item senyor, com jatsie lo guardia appellat de la Albufera sie tengut e aje carrech de guardar be e diligentment la costera de la mar e la devesa e la costera de la Albufera ço es del loch del Puig de Valencie tro al cap de Cullera, pero soven e moftes vegades en les dites costeres fadres e altres males persones furten als pescadors del dit comú; moltes e diverses exarcies, cordes, rems, plom e strops, lences e altres diverses coses a la pesquera axi de la mar com de la Albufera necessaies e oportunes, hoc encara assajen furtar, e han ja furtat, de les barques de la dita pesquera; encara desfan, destrovesen e consumen les barraques dels dits pescadors ço que redunda en gran, evident e irreparable dan 
e prejuhi, no solament de les vostres regalíes, mas encara dels dits pescadors qui tots jorns perden ço del lur per colpa del dit guardia car si be ho tenie aprop segons se pertany negú no furtarie e si u feye los malfeytors e los furts serien trobats, e ara a .x. furts no se'n trobe un. Supplique per tal molt humilment lo dit comú dels pescadors que placie a la vostra Real Magestat estatuir e ordonar que'l dit guardia qui ara es e per temps será no gos o presumesque fer avinentença ab negun dels dits malfeytors sens lo dampnificat e tro que aquell haje cobrat ço del seu o sie satisfeyt e pagat de ço que furtat o pres li será, o del mal que feyt li será. E si lo contrari fará lo dit guardia pach per pena .xx. solidos per cascuna vegada que contraffará applicadors la meytat a vos Senyor e l'altra meytat al dit dampnificat.

38. Item, sie statuit e ordenat que alguna persona no gos o presumesque caçar fotges ni boxas en l'Albufera de Valencia de la festa de Pasqua Florida tro a la festa de /(fol.111v.) sent Miquel, açó declarat que de la festa de sent Miquel tro a la festa de sent Vicent tot hom puxe caçar en la dita Albufera fotges o boxas, pero nengú dins aquest temps no gos parar, caçar ni pendre fotges ni boxes ab quatravara sinó tirant de terra e no de barquą; ni la puxe barquejar. Declarant encara que de la dita festa de sent Vicent tro a la dita festa de Pasqua tot hom puxe caçar e pendre les dites fotges e boxes axi ab quatravara barquejant com tirant de terra, dementres emperó no's acosten a les cabuceres de una milla a totes parts ni facen mal ni dan a nengú. E qui controfará perde la barqua e los ocells e les exarcies e pach per pena cent morabatins applicadors les dues parts a vos Senyor e la terça al dit comú.

39. Item, sie statuit e ordonat que null hom no gos o presumesque calar sepieres del riu del grau de Valencie tro a les senyes del cudolar de levant, ço es en lo embori per la bassa sots pena de .x. morabatins d'or per cascuna vegada applicadores les dues parts a vos Senyor e la terça al acusador. E ultra la dita pena sie tengut pagar lo dan que fet haurá.

40. Item que sie statuit e ordenat que tot hom puxe pescar en l'Albufera de la dita ciutat ab exarcia clara e lícita de la festa de Pasqua de Resurrecció tro al primer dia d'agost. Aço declarat que dins lo dit temps algú no gos pescar en la dita Albufera ab exarcia brana, ço es dolses, cegues ni ab meyans, sots pena de sexanta solidos e cremar la barqua e la exarcia. E aço hage loch en l'any que la gola sie oberta.

41. Item, lo dit comú supplique sie merit de vos Senyort confermar, loar e aprovar tots altres privilegis per los reys passats a dit comú donats e atorgats.

42. Item que'l macip que será afermat ab alcun dels pescadors del dit comú a cert temps, o de certa part, o certa soldada no's gos afermar ab alcun al tre sots pena de star.xx. joms en la presó. E que aquell ab qui's ere afermat ne puxe afermar o haver un altre a tot dan del dit pres. los quals dans lo dit pres li sie tengut satisfer et pagar. O si lo dit son amo volrá, los dits jurats puxen forçar ab grans manaments penals et altres remeys de dret al dit pres que servesque al dit son amo per lo dit temps.

43. Item, que del pex que'ls dits pescadors vendran a la popa de la barcha a mar a altres pescadors qui compren aquell per a esch, ço es per a pendre altre pex et del pex que vendran vora mar per menut a viandans o a mercaders o revenedrors de pex los dits pescadors no sien tenguts pagar alcun delme ni terç de delme ni altre dret; com axi sie stat atorgat per los Reys passats et axi sie estat 
usat et praticat del temps de la conquesta de aquest regne ençá. $E /($ fol. 112) sie plus que notori que'l vostre dret del pex que's ven vor mar per a esch, no valrie ni's arrendarie cinch florins l'any. E per lo pex que's ven per a esch crex lo vostre terç de delme mil solidos cascun any et mes. Encara es plus que notori que'l pex que' ls dits pescadors venen per menut o viandants es tan poch que no toma a res com no sie pescador alcú que en la dita forma vene pex per .xx. solidos l'any poch mes o menys. Quan es plus que notori quel pex que'ls dits pescadors venen a mercaders o revenedors ja paga a vos Senyor tots los dits drets en lo loch on lo dit pex es portat, o venut per los dits mercaders o revenedors. Ad humilem supplicacionem nobis factam pro parte proborum hominum piscatorum predictorum et communis eorumdem; volentes illos favore prosequi gracioso presentis seric cunctis temporibus valiture de nostri certa sciencia et consulte, preinserta capitula et omnia et singula in eis contenta tanquam nobis et nostris regaliis et iuribus, et conservacioni eorundem necnon bono statui dictorum piscatorum et communitati ipsorum no minus utilia quam necessaria, in viam privilegii et alio eo modo quo melius valere et tenere possit, concedimus, laudamus, approbamus, ratificamus, auctoritzamus, et nostre confirmacions presidio roboramus. Mandantes serie cum eadem Illustri et Magnifico Principi Alfonso, Principi Gerunde. primogenito nostro carissimo ac in omnibus regnis et terris nostris Generali Gubernatori, et post dies nostros longevos, Deo propicio, feliciter successori eiusque vicesgerentibus, Baiulo Generali, Justiciis et aliis, inquam, universis officialibus nostris et dicti nostri (Primogeniti infra regnum Valencie et alibi eciam constitutis presentibus et futuris ac locatenentibus eorundem quatenus dicta capitula et unumquodque illorum omniaque et singula in eis contenta et concessionem ac confirmacionem nostras huiusmodi rata, grata et firma habeant teneant; eciam firmiter; et observent, et ab aliis omnibus perpetuo faciant inviolabiliter observari et non contraveniant nec aliquem contravenire) permitant aliqua racione. In cuius rei testimonium presentem fieri et nostro sigillo impendenti iussimus conmuniri. Date Valencie $\mathrm{X}^{\mathrm{a}}$ die Iunii anno a nativitate Domini $\mathrm{M}^{\circ} \mathrm{CCCC}^{\circ} \mathrm{XV}^{\circ}$, regnique nostri quarto. REX FERDINANDUS

Dominus Rex mandavit mihi Paulo Nicholai, et vidit hanc Iohannes Mercaderii. Provisa 